\title{
BRICS: LIQUIDEZ, CONSUMO E RELEVÂNCIA DE POLÍTICAS DE PRODUTIVIDADE E DE COMÉRCIO INTERNACIONAL PARA O IED
}

\author{
BRICS: LIQUIDITY, CONSUMPTION, AND IMPORTANCE OF PRODUCTIVITY AND \\ INTERNATIONAL TRADE POLICIES TO FDI
}

\section{BRICS: LIQUIDEZ, CONSUMO Y IMPORTANCIA DE POLITICAS DE PRODUCTIVIDAD Y COMERCIO INTERNACIONAL PARA LAS IED}

Recebido em: 03/04/2017

Avaliado em: 16/06/2019

Reformulado em:20/01/2020

Aceito para publicação em: 10/04/2020

Publicado em: 02/09/2020

Editor Responsável: Tarcísio Silva

\author{
Andre Taue Saito ${ }^{1}$ \\ Nuno Manoel Martins Dias Fouto ${ }^{2}$ \\ Cláudio Felisoni de Angelo ${ }^{3}$
}

\section{RESUMO}

É avaliada a relação da expansão da liquidez ao setor privado e dos fluxos de IED com o Consumo no BRICS. Os resultados das regressões de dados em painel empregadas indicam que: (i) enquanto o IED tem relação negativa com o Consumo, há a ligação positiva entre o Crédito Bancário e o Consumo, e este não tem persistência; (ii) o relacionamento do Consumo com Crédito Bancário é maior do que com a Riqueza Financeira, a Riqueza Humana e o IED; e iii) a majoração da produção é orientadora do IED. Com base nestes resultados o artigo contribui aos estudos acerca do Crédito Bancário, Consumo e IED, bem como aos formuladores de políticas econômicas, cujas decisões impactam a Contabilidade Nacional, com as seguintes recomendações: no BRICS, o Consumo não é o orientador do IED, mas a majoração da produção interna do país que, caso não seja consumida internamente, pode ser direcionada ao exterior. Neste sentido, para atrair o IED, é importante estimular a produtividade e o aumento das exportações simultaneamente. Além disso, dada a ligação entre Consumo e Crédito Bancário, e entre Crédito Bancário e estabilidade monetária, merece atenção a relação entre as políticas de estabilidade monetária e de sustentação do Consumo pelo crescimento do Crédito Bancário. Isso porque o Crédito Bancário pode alcançar níveis elevados de difícil adequação, ocasionando aumento da instabilidade econômica no longo prazo.

Palavras-chave: Consumo; Crédito; Crédito Bancário; Investimento Estrangeiro Direto; Modelos para Dados em Painel.

\footnotetext{
${ }^{1}$ Doutor em Administração pela Universidade de São Paulo (USP); Professor de Finanças da Universidade Federal de São Paulo (UNIFESP); E-mail: andretauesaito@gmail.com

${ }^{2}$ Doutor em Administração pela Universidade de São Paulo (USP); Professor do Departamento de Administração da Universidade de São Paulo (USP); E-mail: nfouto@usp.br

${ }^{3}$ Doutor em Economia pela Universidade de São Paulo (USP); Professor do Departamento de Administração da Universidade de São Paulo (USP); E-mail: cfa@usp.br
} 


\begin{abstract}
The relationship between liquidity to the private sector, FDI and Consumption at BRICS is assessed. The results of the panel data regressions indicate that: (i) while FDI has a negative relationship with Consumption, there is a positive signal between Bank Credit and Consumption, which has no persistence; (ii) Consumption's relationship with Bank Credit is greater than with Financial Wealth, Human Wealth and FDI; and iii) the increase in production is guiding FDI. Based on these results, the article contributes to studies on Bank Credit, Consumption and FDI, as well as to economic policy makers whose decisions impact National Accounts with following recommendations: at BRICS, Consumption does not attract FDI, but the increase in domestic production does. In this sense, in order to attract FDI, it is important to stimulate both productivity and increase exports simultaneously. Moreover, as there is a link between Consumption and the Bank Credit growth, and between Bank Credit and monetary stability, it is important to realize relationship between both policy of monetary stability and policy of Consumption supported by the growth of Bank Credit. As Bank Credit can reach high levels, economic instability can increase in long term.
\end{abstract}

Keywords: Bank Credit; Consumption; Credit; Foreign Direct Investment; Models for the Data in the Panel.

\title{
RESUMEN
}

Se evaluó la relación entre liquidez para el sector privado, IED y Consumo en BRICS. Los resultados de las regresiones de datos del panel indican que: (i) si bien la IED tiene una relación negativa con el Consumo, existe una señal positiva entre el Crédito Bancario y el Consumo, que no tiene persistencia; (ii) La relación de Consumo con el Crédito Bancario es mayor que con la Riqueza Financiera, la Riqueza Humana y la IED; y iii) El Consumo no está guiando la IED, sino más bien el aumento de la producción. Con base en estos resultados, el artículo contribuye a los estudios sobre Crédito Bancario, consumo e IED, así como a los responsables de la política económica cuyas decisiones afectan a las cuentas nacionales con las siguientes recomendaciones: en BRICS, el Consumo no atrae IED, pero el aumento de la producción nacional sí. En este sentido, para atraer IED, es importante estimular tanto la productividad como aumentar las exportaciones simultáneamente. Además, dado que existe un vínculo entre el Consumo y el crecimiento del Crédito Bancario, y entre el Crédito Bancario y la estabilidad monetaria, es importante tener en cuenta la relación entre la política de estabilidad monetaria y la política de consumo respaldada por el crecimiento del Crédito Bancario. Como el Crédito Bancario puede alcanzar altos niveles, la inestabilidad económica puede aumentar a largo plazo.

Palabras-clave: Consumo; Crédito Bancario; Crédito; Inversión Extranjera Directa; Regresión de Datos de Panel.

\section{INTRODUÇÃO}

\subsection{Problema e questão de pesquisa}

O crescimento do fluxo do IED - Investimento Estrangeiro Direto - visualizado no painel (e) da Figura 1 no BRICS - Brasil, Rússia, Índia, China e África do Sul - motivou o desenvolvimento de estudos de seus determinantes.

O IED é tratado usualmente como variável dependente, como em Vijayakumar, Sridharan e Rao (2010), Jadhav (2012) e Laskar (2015), para identificar os fatores relacionados ao seu incremento e, dentre eles, o mercado interno de consumo é avaliado (De Angelo, Eunni, \& Fouto, 2010). Embora o estudo da relação do nível de consumo das famílias - doravante Consumo - com o IED seja 
relevante não se observa constância de análises a respeito da orientação do IED ao Consumo no BRICS.

Uma das variáveis importantes relacionadas ao Consumo é o Crédito Bancário, e o crescimento significativo deste levou o FMI (2011) a considerá-lo uma ameaça à estabilidade econômica. Para ilustrar esta conjuntura, o BRICS registrou incremento da razão Crédito/PIB, doravante Crédito Bancário, de aproximadamente 50\%, em 2003, para 80\%, em 2014 (Banco Mundial, 2016).

Neste sentido, há uma oportunidade de analisar se o Crédito Bancário e o IED estão orientados ao Consumo, tratando este como variável dependente, e assim o artigo tem como questão central: Qual a relação do IED e do Crédito Bancário com o Consumo?

\subsection{Hipóteses, objetivo central e estrutura do artigo}

Para respondê-la, são aplicadas regressões de dados em painel, e três hipóteses fundamentadas nas seções seguintes são:

(a) Hipótese 1: há relação positiva do Crédito Bancário e do IED com o Consumo que teve persistência;

(b) Hipótese 2: o relacionamento do Consumo com a Riqueza Financeira, o Crédito Bancário e o IED é maior do que com a Riqueza Humana; e

(c) Hipótese 3: a Taxa de Empréstimos, a Inflação, o Crédito Não-Performado, a Força do Credor, o Enforcement e o Crescimento Econômico se relacionaram com o Crédito Bancário que tem persistência no tempo.

Como o Consumo tem vínculo com a Riqueza, o Crédito Bancário e o IED, a Hipótese 1 e a Hipótese 2 possibilitarão a verificação estatística de como essa associação ocorre no BRICS e se o Consumo sofre maior influência da Riqueza Financeira, do Crédito Bancário e do IED que são elementos mais exógenos à remuneração dos fatores de produção, em comparação à Riqueza Humana.

Na Hipótese 3, será investigado quais dos fatores determinantes do Crédito Bancário são os significativos no BRICS, de forma a ser possível compreender quais as variáveis estudadas na literatura ligadas ao Crédito Bancário têm significância estatística e que, por sua vez, possuem de certo modo associação com o Consumo no contexto em que o BRICS esteve em eminência favorável entre os anos de 2003 e 2014, aprofundando os trabalhos de Saito (2012), Saito, Savoia e Lazier (2013) e Bhue, Prabhala e Tantri (2015), porém enfatizando-se o caso deste grupo de países e o vínculo entre Crédito Bancário e o Consumo.

Assim, o objetivo central do presente trabalho é avaliar se a expansão da liquidez bancária ao setor privado e os fluxos de IED estão voltados ao Consumo no BRICS, com base em dados do período compreendido entre 2003 e 2014, quando este grupo de países esteve em eminência positiva e foi caracterizado pela expansão de liquidez ao setor privado, pelo crescimento da renda per capita e aumento do fluxo de IED.

Este artigo, após esta seção introdutória, apresentará a fundamentação teórica das hipóteses com base nas pesquisas da literatura e nos dados econômicos registrados pelo BRICS. Em seguida, explicará a metodologia da pesquisa empírica, com a apresentação dos modelos de dados em painel e a operacionalização das variáveis. Além disso, discorrerá acerca dos resultados obtidos pelas regressões em relação ao Consumo e ao Crédito Bancário, iniciadas pelo modelo de painel fixo e aprofundadas pelo modelo de painel dinâmico que permitirá a obtenção de resultados mais robustos e controlados, bem como a identificação de uma eventual inércia das variáveis estudadas. Por fim, apresentará a conclusão acerca da pesquisa realizada. 


\section{REFERENCIAL TEÓRICO}

\subsection{Orientação ao Consumo}

Esta seção expõe o raciocínio envolvido, com base nas pesquisas e dados empíricos, na definição da Hipótese 1 e da Hipótese 2 deste artigo.

A Hipótese do Ciclo de Vida (Modigliani \& Brumberg, 1954) e a Teoria do Rendimento Permanente (Friedman, 1957) abordam o Consumo e explicam ser a Riqueza o elemento relevante a sua determinação. Em ambas, o Consumo decorre do valor dos ativos - Riqueza Financeira - e do valor da renda - Riqueza Humana - cujos aumentos não previstos seriam distribuídos no período remanescente de vida e incrementariam o Consumo.

Na literatura verifica-se, em pesquisas, a relação da Riqueza (Davis \& Palumbo, 2001; Mehra, 2001; Bertaut, 2002; Donihue \& Avramenko, 2007; Shen, Holmes, \& Lim, 2015) e do Crédito Bancário (Ellis, 2005) no Consumo, ou seja, a Riqueza Humana, a Riqueza Financeira e o Crédito Bancário influenciam o Consumo.

Figura 1 - Evolução das variáveis estudadas na Hipótese 1 e na Hipótese 2

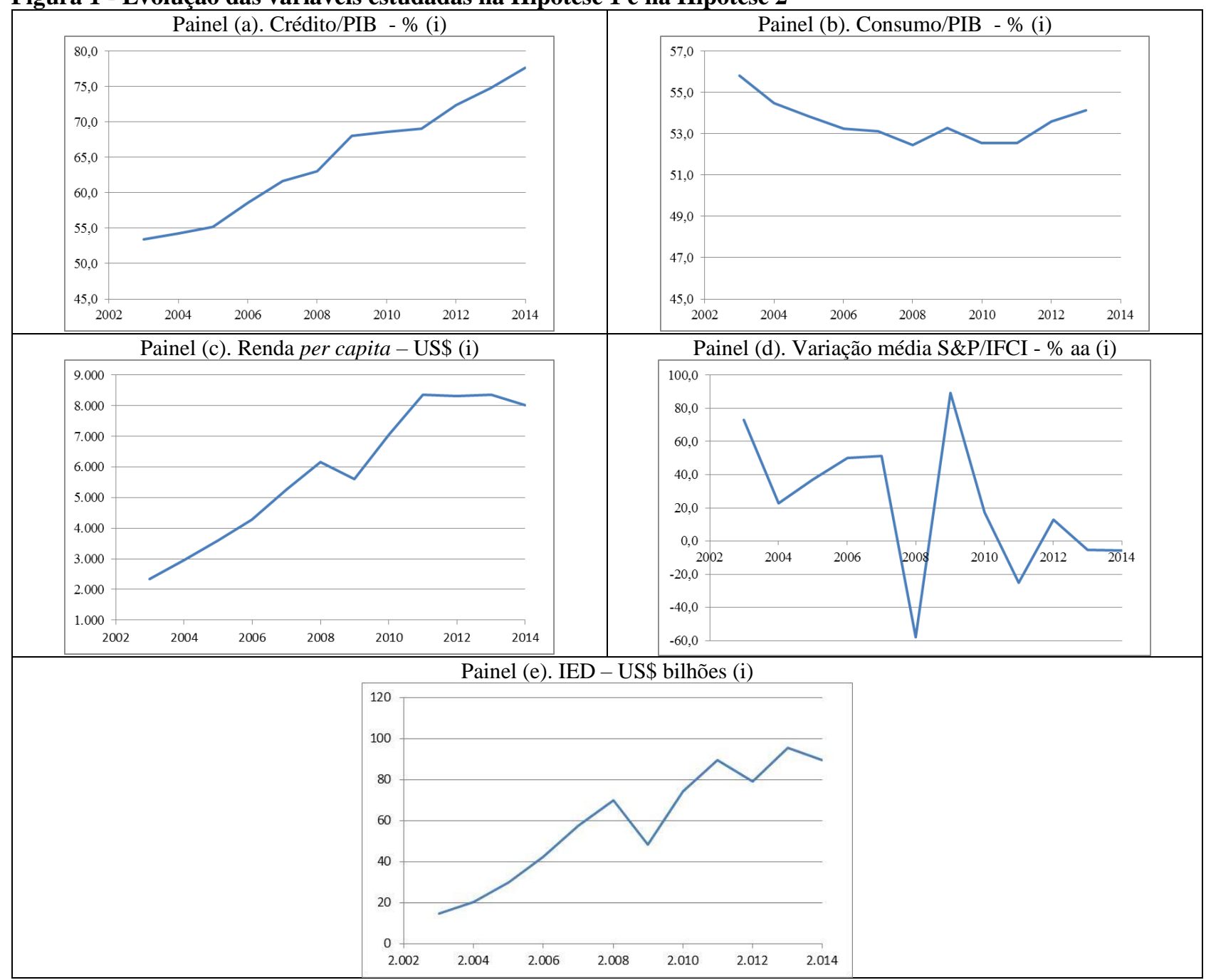

Fonte: (i) Elaboração pelos autores, mensurando-se as médias dos BRICS, com base em dados disponibilizados pelo Banco Mundial (2016).

Como no BRICS houve o crescimento do Crédito Bancário - Painel (a) da Figura 1 - e do IED - Painel (e) da Figura 1 -, é plausível investigar se a intensificação de liquidez proporcionada 
pelos bancos ao setor privado e o fluxo de investimentos estrangeiros estiveram associados positivamente com a sustentação do Consumo - Painel (b) da Figura 1.

Embora o Crédito Bancário e o IED apresentem ligações com Consumo, estas não são perceptíveis nestas figuras. Assim, é oportuna Hipótese 1 e avaliar se há relação positiva do Crédito Bancário e do IED com o Consumo, bem como se este teve persistência.

Além de avaliar se tal conexão ocorre em mesmo sentido e com significância estatística, é importante analisar se a Riqueza Financeira, o Crédito Bancário e o IED tiveram maior associação do que a Riqueza Humana, pois esta é mais diretamente relacionada à remuneração dos fatores de produção.

Assim, procura-se avaliar se fatores mais exógenos à remuneração dos fatores de produção realmente são mais significativos e de maior impacto ao Consumo. Neste artigo, a Riqueza Humana é representada pela renda per capita - Painel (c) da Figura 1 - e a Riqueza Financeira pela evolução do S\&P/IFCI dos BRICS - Painel (d) da Figura 1.

Apesar das associações existentes na teoria, não é possível atestar na Figura 1 que a Riqueza Financeira e o Crédito Bancário apresentem maior vínculo do que a Riqueza Humana tem com o Consumo no BRICS. Contudo, como observar se a hegemonia de fatores exógenos à remuneração dos fatores de produção é relevante, este trabalho investiga a Hipótese 2 de o relacionamento do Consumo com a Riqueza Financeira, o Crédito Bancário e o IED ter sido maior do que com a Riqueza Humana.

\subsection{Fatores Determinantes do Crédito Bancário}

Nesta seção, a pesquisa da literatura de crédito exposta permite a identificação de variáveis associadas ao Crédito Bancário, em linha com Saito (2012) e Saito, Savoia e Lazier (2013), e que são importantes porque, uma vez identificada a orientação do Crédito Bancário ao Consumo, é possível compreender quais fatores determinantes do Crédito Bancário têm significância estatística e que, por sua vez, apresentam de certa forma ligação com o Consumo no contexto em que o BRICS esteve em evidência favorável (i. e. entre os anos de 2003 e 2014).

Em relação ao Crédito Bancário, inicialmente os estudos sobre seus fatores determinantes podem ser divididos em duas correntes.

Em uma delas, há o destaque à maior propensão à concessão de crédito decorrente de melhor conhecimento prévio do histórico e da reputação dos tomadores, (Jaffee \& Russel, 1976; Stiglitz \& Weiss, 1981; Pagano \& Jappelli, 1993; Jappelli \& Pagano, 2002; Sapienza, 2002).

Outra corrente formalizada por Townsend (1979), Aghion e Bolton (1992) e Hart e Moore (1994; 1998) avalia a importância da solidez institucional na proteção dos credores. Nela se observa que países adotantes do modelo civil inglês são menos burocráticos, tem menores índices de Enforcement e de corrupção, e oferecem maior segurança jurídica aos credores em relação àqueles embasados no modelo romano-germânico (La Porta et al, 1996, 1997, 1998, 1999, 2000, 2002; Djankov, Glaeser, La Porta, Lopez-de-Silanes, \& Shleifer, 2003).

Saito (2012) destaca que ambas as correntes não são excludentes e o que une as duas correntes é a proteção ao credor, sendo fundamental a sua eficácia (Galindo \& Micco, 2005; Hale, Razin, \& Tong, 2006; 2009). Isso porque há países mais dependentes de mecanismos de acesso prévio à informação dos tomadores, pois possuem sistemas legais menos robustos (Jappelli \& Pagano, 2002, Djankov et al, 2003; Mulligan \& Shleifer, 2005; Jappelli, Pagano, \& Bianco, 2005). Nessa linha, Diamond (2004) e Desai, Foley e Hines (2004) concluíram que os agentes financeiros locais têm vantagem competitiva em relação aos credores estrangeiros, porque usufruem de maior acesso às informações dos tomadores. Os estrangeiros são mais dependentes do sistema legal para a recuperação de créditos não recebidos (Esty, 2004; Mian, 2006).

Araujo e Funchal $(2006 ; 2007)$ entenderam que as características da lei de falências de um país implicam o grau de desenvolvimento do mercado de crédito. Haselmann, Pistor e Vig (2006) 
concluíram que ela é significativa ao fortalecimento da proteção ao credor, quando estudaram economias em desenvolvimento entre 1995 e 2002.

Além disso, Djankov, Mcliesch e Shleifer (2007) encontraram relação positiva entre o volume de crédito e a Força do Credor ao estudarem cento e vinte e nove países entre 1978 e 2003, corroborando Jappelli e Pagano (2002).

Por Força do Credor entende-se a quantidade de leis que protegem os direitos do credor. Em seguida, Warnock e Warnock (2008) avaliaram em sessenta e dois países entre 2001 e 2005 que o incremento do crédito ocorre quando maiores forem a Força do Credor e a estabilidade monetária, representada pela Inflação.

Bae e Goyal (2009) corroboram esses autores ao estudarem o painel de dados bancários de quarenta e oito países entre 1994 e 2003, e concluíram que a Força do Credor foi importante ao volume de crédito em adição à proteção dos direitos de propriedade. Assim, nota-se o foco dos estudos na Força do Credor como determinante do volume de crédito e a importância da estabilidade econômica a este fim.

Mas tal ênfase descrita acerca dos trabalhos sobre o assunto sofreu alterações. Não se pretende atribuir a essas alterações um único motivo, mas a eclosão da crise econômica provavelmente esteja relacionada.

Como exemplo, Affinito e Tagliaferri (2010), investigaram o mercado italiano de 2000 a 2006, e constataram que o uso de securitização ocorreu em maiores níveis tanto em bancos menos capitalizados e com carteiras de crédito de maior risco e de menores margens de rentabilidade, como em instituições de maior crescimento da carteira de empréstimos.

A possibilidade de transferência de riscos e a integração entre o mercado de crédito e de capitais são acontecimentos importantes ao crescimento do nível de empréstimos. Estes achados estão em linha com Minksy (1992) e Deos (1998) acerca de as inovações financeiras sustentarem o crescimento do mercado de crédito. Tal majoração, segundo Silipo (2011), está relacionada ao aumento da confiança dos agentes superavitários, influenciada não somente pelo desenvolvimento da securitização, mas pelo incremento das margens das instituições financeiras e do valor dos ativos.

Nesse sentido, o ciclo de negócios possui efeitos sobre a carteira de empréstimos e Glen e Mondragón-Vélez (2011) identificaram que o melhor desempenho dos portfolios de crédito dos bancos comerciais, medido pela provisão de perdas, entre 1996 e 2008 tem o crescimento econômico como principal direcionador. Esse aspecto é importante, pois está relacionado com a propensão de os bancos ofertarem maior volume de crédito ao setor privado. Se isso for verdadeiro, o crescimento econômico estaria relacionado à menor provisão de perdas e, consequentemente, ao maior nível de empréstimo.

No entanto, caso haja alteração a um cenário de menor crescimento ou até mesmo de retração das atividades econômicas o volume de crédito não se reduziria facilmente, pois é factível crer em uma inércia do estoque de crédito.

Em Silipo (2011) e Glen e Mondragón-Vélez (2011), não há respostas conclusivas se a existência de créditos Não-Performados - não apenas a provisão - tem relação negativa com o volume de crédito. Contudo, o ritmo de crescimento econômico está relacionado com ciclos de Minsky (1992) ou com os choques de Stiglitz e Greenwald (2004). Observa-se que o foco desses estudos recaiu sobre os mecanismos de securitização e o crescimento econômico, ambos relacionados ao volume de crédito.

De qualquer modo, é possível a identificação de variáveis econômicas e institucionais, como fatores ordenados ao volume de crédito e os estudos seguintes os abordam. Tsai, Chang e Hsiao (2011) verificaram que os maiores bancos multinacionais preferem expandir suas operações em países que possuem bureaus de crédito e oferecem informações de melhor qualidade sobre os devedores. 
Saito, Savoia e Lazier (2013), por sua vez, observaram que a Taxa de Empréstimo, o Enforcement, o Crescimento Econômico e a Força do Credor foram estatisticamente significativos para o nível de crédito privado nos países emergentes, entre 2004 e 2010.

Figura 2 - Evolução das Variáveis Estudadas na Hipótese 3

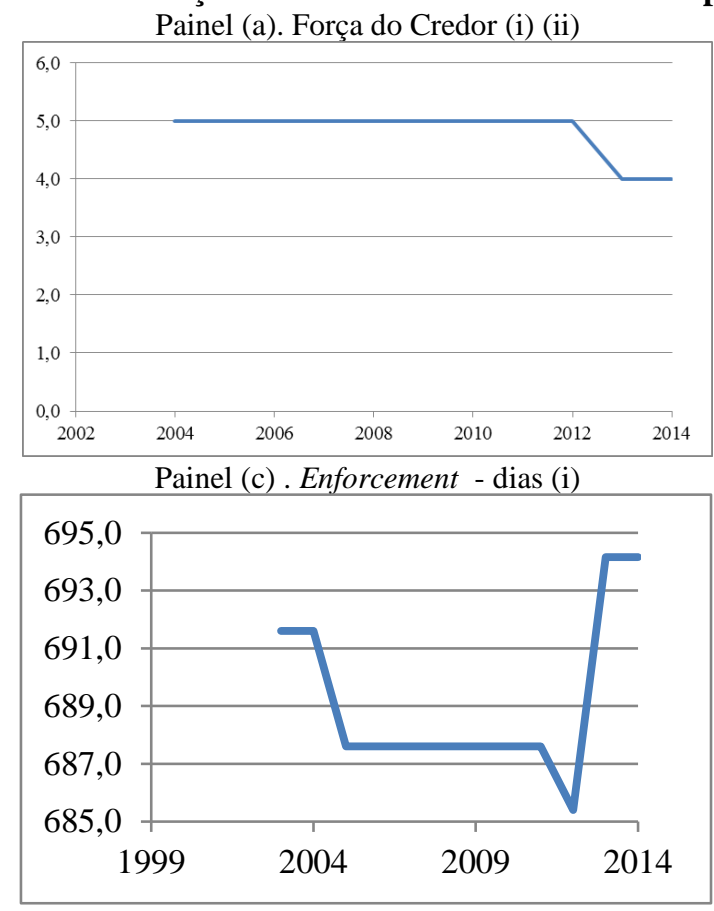

Painel (e). Taxa de Empréstimo - \% aa (i)

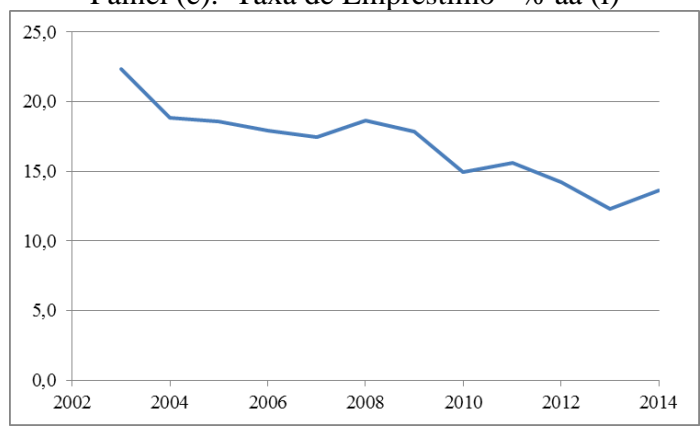

Painel (b). Taxa de Inflação - \% (i)

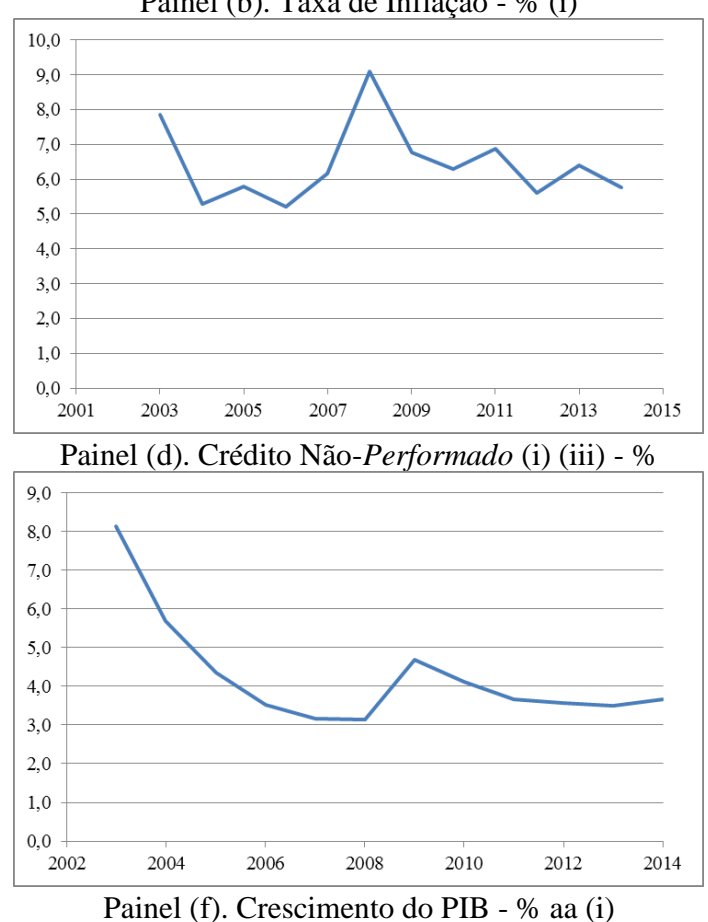

Painel (f). Crescimento do PIB - \% aa (i)

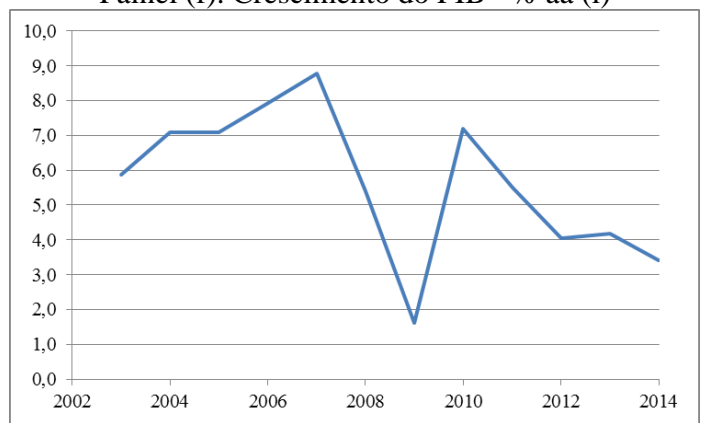

Fonte: (i) Elaboração pelos autores, mensurando-se as médias dos BRICS, com base em dados disponibilizados pelo Banco Mundial (2016); (ii) A Força do Credor é a mediana, se refere a uma escala de 1 a 12 e é explicado nos procedimentos metodológicos; (iii) Percentual de créditos a receber pelos bancos, mas em atraso, em relação ao total de empréstimos.

E Bhue, Prabhala e Tantri (2015) constataram a relação positiva entre a Força do Credor e o Crédito Bancário, para a Índia. Assim, é plausível crer na associação positiva da Força do Credor, se a quantidade de leis realmente estiver ligada a maior disponibilidade de crédito, pois os estudos anteriores, em geral, assim evidenciaram. O caso de exceção está em Saito, Savoia e Lazier (2013) que atribuíram à relação contrária a possiblidade de não ser a quantidade de leis de proteção ao credor e, sim, sua eficácia.

A Força do Credor - Painel (a) da Figura 2 - teve comportamento médio estável na maior parte do período e isso será investigado. Por sua vez, espera-se a relação negativa do Crédito Bancário com a Inflação e o maior tempo de Enforcement. Entre 2003 e 2014, estas variáveis foram instáveis no BRICS - Painel (b) e Painel (c) da Figura 2 - e, visualmente, não há possibilidade de maiores afirmações. 
A associação contrária do Crédito Não-Performado - Painel (d) da Figura 2 - e da Taxa de Empréstimo - Painel (e) da Figura 2 - ao Crédito Bancário - Painel (a) da Figura 1 - é factível, no BRICS, e corroborada quando se visualiza nas figuras. Mas é prudente avaliar com mais zelo assim como o Crescimento Econômico - Painel (f) da Figura 2 - do qual não é possível maiores inferências visualmente.

Diante do apresentado, há conexão teórica da Taxa de Empréstimo, da Inflação, do Crédito Não-Performado, da Força do Credor, do Enforcement e do Crescimento Econômico com o Crédito Bancário. Este estudo identifica quais dessas variáveis são significativas no BRICS e como se relacionam com o Crédito Bancário, ao investigar a Hipótese 3 de que a Taxa de Empréstimos, a Inflação, o Crédito Não-Performado, a Força do Credor, o Enforcement e o Crescimento Econômico se relacionaram com o Crédito Bancário que tem persistência no tempo.

\section{PROCEDIMENTOS METODOLÓGICOS}

\subsection{Modelos de Painel}

Para estimar os coeficientes dos modelos, utilizou-se a regressão de dados em painel, que combina dados em corte transversal e em série de tempo, conforme equação a seguir (Wooldridge, 2010)

$$
Y_{i t}=a+b_{1} X_{i t 1}+b_{2} X_{i t 2}+\ldots . .+u_{i t}
$$

Sendo: $i=1, \ldots ., \mathrm{n}$ países; $t=1, \ldots ., \mathrm{t}$ períodos de tempo; $Y=$ a variável dependente; e $X=$ vetor das variáveis explicativas.

O painel estático será empregado em duas situações.

Na primeira - Modelo de Consumo - a variável dependente é o Consumo e as independentes são: Crédito Bancário, Riqueza Humana, Riqueza Financeira e o IED.

Na segunda - Modelo de Crédito Bancário - a variável dependente é o Crédito Bancário e as independentes são: Taxa de Empréstimo, Crédito Não-Performado, Inflação, Força do Credor, Enforcement e Crescimento Econômico. Nos modelos de painel estático, é empregada a abordagem de Efeitos Fixos, como forma de controlar o efeito de variáveis omitidas e que são constantes ao longo do tempo de estudo, como idioma e regime político, por exemplo. Para a verificação destes efeitos não observáveis, isto é, heterogeneidade não observada, os testes de Chow e Breusch-Pagan são realizados.

No corpo do artigo os resultados das regressões dos modelos de Efeitos Fixos são calculados com erros-padrão robustos e oferecem uma visão inicial exploratória sobre os coeficientes.

Tais modelos são comumente empregados no estudo de dados em painel, mas é necessária a exogeneidade estrita dos regressores para suas estimativas serem consistentes, o que implica o termo de erro do modelo ser não correlacionado com as variáveis independentes em todo instante de tempo.

Caso essa exogeneidade não ocorra, é necessária a adoção de abordagens em que os regressores correlacionados com os termos de erro sejam substituídos por estimativas que não apresentem esta correlação. Estes regressores substitutos são as denominadas variáveis instrumentais que, além de serem não correlacionadas com as variáveis explicativas endógenas, devem ser não correlacionadas com o termo de erro.

Como instrumento, é usual a utilização de defasagens das variáveis regressoras por meio da abordagem conhecida como Método dos Momentos Generalizados - MMG - de Arellano e Bond (1991), Arellano e Bover (1995) e Blundell e Bond (1998). Arellano e Bond (1991) propõem a transformação dos regressores com a obtenção da primeira diferença, o que elimina a heterogeneidade não observada. Os resíduos, portanto, tendem a ser autocorrelacionados, tornando necessária a aplicação de testes de autocorrelação propostos por ambos; espera-se uma autocorrelação de primeira ordem negativa e autocorrelação de segunda ordem não significativa. 
Com a redução de observações, ao se utilizar a primeira diferença, os instrumentos podem ser fracos e a haver endogeneidade, aspecto acentuado em painéis desbalanceados e de dimensão temporal reduzida.

Assim, há a sugestão de Arellano e Bover (1995) e Blundell e Bond (1998), para a utilização de um sistema. O aperfeiçoamento da MMG em diferenças - MMG Dif - é o modelo de Blundell e Bond (1998), denominado MMG sistêmico - MMG Sis - que é um sistema de equações, no qual a primeira diferença é empregada como instrumento nas equações em nível, e os instrumentos das equações em primeiras diferenças são as variáveis em nível defasadas.

Para a validação dos instrumentos são importantes os testes de sobreidentificação, como o de Sargan (1958) e de Hansen (1982), tanto no MMG Dif como no MMG Sis. Os estimadores MMGDif e MMG-Sis podem ser de um ou dois passos, sendo este assintoticamente mais eficiente que o de um passo, mas com erros padrão possivelmente enviesados para baixo (Arellano e Bond, 1991; Blundell e Bond, 1998), o que torna seus resultados imprecisos principalmente para amostras finitas e com número elevado de instrumentos.

Para a obtenção de estimativas de erros padrão, corrigidas em amostras finitas, e com tratamento para a heteroscedasticidade, é requerida a correção na matriz de covariâncias sugerida por Windmeijer (2005). Assim, os procedimentos mencionados nesta seção são importantes à consecução de Modelos de Painel Dinâmico, robustos em relação à heterocedasticidade, autocorrelação e normalidade. Nos modelos de regressão, o nível de significância é 0,05.

\subsection{Operacionalização das Variáveis Utilizadas nas Regressões}

A amostra é composta por Brasil, Rússia, Índia, China e África do Sul, e são utilizados dados disponíveis no Banco Mundial, coletados para o período entre 2003 e 2014. Nas regressões, foi realizada a transformação monotônica dos dados em logaritmo natural, a qual facilita a compatibilização de escalas, auxilia na estabilização das variâncias e lineariza possíveis tendências exponenciais, característica comum em séries econômicas e financeiras, conforme Hendry (1997).

A seguir, as variáveis deste estudo e os sinais esperados pelos seus coeficientes nas regressões em relação ao Consumo e ao Crédito Bancário, com base na literatura que é caracterizada pelo uso da regressão de dados em painel estático. Ressalta-se que o presente artigo fará o emprego da regressão de dados em painel dinâmico para capturar eventual inércia das variáveis e obter resultados mais robustos e controlados:

Consumo: é o índice obtido pela divisão do Consumo Famílias pelo PIB anual de cada país.

Riqueza Humana: representada pela renda per capita.

Riqueza Financeira: tem como proxy a variação anual em dólar de ações de empresas integrantes dos índices S\&P/IFCI de cada país.

Para a Riqueza Humana e Riqueza Financeira, espera-se sinal positivo de seus coeficientes na regressão com o Consumo (Davis \& Palumbo, 2001; Mehra, 2001; Bertaut, 2002; Donihue e Avramenko, 2007; Shen, Holmes, \& Lim, 2015).

IED: é o fluxo de investimento estrangeiro direto.

Em De Angelo, Eunni e Fouto (2010), por exemplo, o mercado interno é um fator determinante do IED com sinal positivo. Assim, espera-se relação positiva na regressão do IED com o Consumo.

Crédito Bancário: é a razão entre Crédito Bancário e o PIB.

Espera-se o sinal positivo de seu coeficiente na regressão com o Consumo, seguindo o raciocínio de Ellis (2005).

Taxa de Empréstimo: corresponde à média de empréstimo de cada economia.

Espera-se sinal negativo de seu coeficiente, na regressão com o Crédito Bancário, seguindo o raciocínio de Ellis (2005).

Inflação: é a taxa oficial de cada país. 
O sinal negativo do coeficiente, na regressão com o Crédito Bancário, reflete a ligação do aumento geral do nível de preços com as decisões financeiras dos credores; haveria indícios de a instabilidade monetária estar associada à redução da disponibilidade de recursos de credores, coerente com Cruz (2004) e Warnock e Warnock (2008).

Crédito Não-Performado: é a razão entre os créditos a receber pelos bancos, mas em atraso, e o volume de empréstimos contabilizados em seus balanços.

Em Silipo (2011) e Glen e Mondragón-Vélez (2011), não houve respostas conclusivas, embora esperassem uma relação negativa entre o Crédito Não-Performado e o Crédito Bancário. falimentares.

Força do Credor: retrata o grau de proteção ao credor através da existência de leis

Esta variável é utilizada por autores como Haselmann, Pistor e Vig (2006), Djankov, Mcliesch e Shleifer (2007), Warnock e Warnock (2008), Bae e Goyal (2009), De Haas, Ferreira e Taci (2010), La Porta et al (1997; 1998). Utiliza-se o indicador do Banco Mundial e que mensura o grau de proteção ao credor. Trata-se de um índice escalar, de acordo com a existência das leis falimentares consideradas pela instituição e compreendido entre zero e doze, sendo este o maior nível (Banco Mundial, 2016). Espera-se que seja positivamente relacionado com o nível de Crédito Bancário (Haselmann, Pistor, \& Vig, 2006; Djankov, Mcliesch, \& Shleifer, 2007; Warnock \& Warnock, 2008; Bae \& Goyal, 2009; De Haas, Ferreira, \& Taci, 2010):

Enforcement: É o número de dias entre o início do processo judicial e a observância de um contrato, com o pagamento da dívida pelo devedor.

Avalia a agilidade do judiciário, esperando-se relação negativa com o Crédito Bancário (Djankov, Mcliesch \& Shleifer, 2007).

Crescimento Econômico: é a variação anual do PIB.

O resultado a ser encontrado pode estar de acordo com os ciclos de Minsky (1992), ou com os choques de Stiglitz e Greenwald (2004). Dessa forma, avalia-se se os níveis das atividades econômicas apresentam relação positiva com o Crédito Bancário.

\section{RESULTADOS E ANÁLISE DA PESQUISA EMPÍRICA}

\subsection{Estatísticas Descritivas}

A seguir, as medidas de posição e de dispersão (Tabela 1).

Tabela 1 - Medidas de Posição e de Dispersão

\begin{tabular}{lrrrrrr}
\hline \multicolumn{1}{c}{ Variável (i) } & \multicolumn{1}{c}{ Média } & \multicolumn{1}{c}{ Mediana } & \multicolumn{1}{c}{ Mínimo } & \multicolumn{1}{c}{ Máximo } & \multicolumn{1}{c}{ D. P. (ii) } & C. V. (iii) \\
\hline Consumo - \% & 53,94 & 58,49 & 35,32 & 63,39 & 9,01 & 0,17 \\
Crédito Bancário - \% & 64,73 & 52,85 & 21,24 & 141,80 & 32,26 & 0,49 \\
Riqueza Humana - US\$ & $5.858,70$ & $5.617,20$ & 565,34 & 14.49 & $3.999,96$ & 0,68 \\
Riqueza Financeira - \% aa & 21,61 & 17,96 & $-73,43$ & 125,11 & 44,43 & 2,05 \\
IED - US\$ bilhões & 24,01 & 24,27 & 20,25 & 26,39 & 1,45 & 0,06 \\
Crédito Bancário - \% & 64,73 & 52,85 & 21,24 & 141,80 & 32,26 & 0,49 \\
Crédito Não-Performado - \% & 4,27 & 3,45 & 0,95 & 20,40 & 3,21 & 0,75 \\
Inflação - \% aa & 6,43 & 6,00 & $-0,70$ & 14,72 & 3,41 & 0,53 \\
Taxa de Empréstimo - \% aa & 16,87 & 10,78 & 5,31 & 67,08 & 15,29 & 0,91 \\
Força do Credor - 0 a 12 & 5,13 & 5,00 & 2,00 & 8,00 & 1,76 & 0,34 \\
Enforcement - dias & 689,18 & 600,00 & 267,00 & $1.420,00$ & 400,74 & 0,58 \\
Crescimento Econômico - \% aa & 5,68 & 5,62 & $-7,82$ & 14,20 & 3,82 & 0,67 \\
\hline
\end{tabular}

(i) unidades de medidas originais. Nas regressões foi realizada a transformação monotônica dos dados em logaritmo natural, conforme explicado na seção Operacionalização das Variáveis Utilizadas nas Regressões; (ii) Desvio Padrão; (iii) Coeficiente de variação.

Na Tabela 1, embora a amplitude e a dispersão das variáveis chamem a atenção, não é possível afirmar se características que diferem entre os países e são constantes no tempo são relevantes como 
variáveis explicativas para o Consumo e o Crédito Bancário. Assim, com as regressões a serem apresentadas nas demais seções, será possível verificar se esta situação ocorre.

\subsection{Modelo de Consumo: a Maior Influência do Crédito Bancário no Consumo e outros Resultados Econômicos}

Tabela 2 - Resultados dos Painéis Estáticos do Modelo de Consumo (I) (II)

\begin{tabular}{|c|c|c|c|c|c|c|}
\hline Coeficientes & (I) & (II) & (III) & (IV) & $(\mathbf{V})$ & $(\mathrm{VI})$ \\
\hline \multirow[t]{2}{*}{ Constante } & 0,56356 & 0,520974 & 0,649073 & 0,665823 & 0,664287 & 0,729432 \\
\hline & {$[0,00000]$} & {$[0,00000]$} & {$\left[2,82.10^{-19}\right]$} & {$\left[2,02,10^{-13}\right]$} & {$\left[9,66,10^{-25}\right]$} & {$\left[2,14,10^{-8}\right]$} \\
\hline \multirow[t]{2}{*}{ Crédito Bancário } & 0,14037 & 0,133409 & 0,153728 & 0,147010 & 0,156970 & 0,151920 \\
\hline & {$[0,00003]$} & {$[0,0002]$} & {$\left[2,35,10^{-7}\right]$} & {$\left[3,89,10^{-5}\right]$} & {$\left[1,21.10^{-9}\right]$} & {$\left[6,69.10^{-7}\right]$} \\
\hline \multirow[t]{2}{*}{ Riqueza Humana } & $-0,024114$ & $-0,0175936$ & $-0,0186684$ & $-0,0200826$ & $-0,0172814$ & $-0,0205529$ \\
\hline & {$[0,00000]$} & {$[0,0375]$} & {$\left[7,09.10^{-6}\right]$} & {$[0,0122]$} & {$[0,0012]$} & {$[0,0072]$} \\
\hline \multirow[t]{2}{*}{ Riqueza Financeira } & 0,0024646 & 0,00581351 & 0,0007179 & 0,00480027 & 0,000781073 & 0,0050868 \\
\hline & {$[0,42982]$} & {$[0,4044]$} & {$[0,8483]$} & {$[0,4176]$} & {$[0,8353]$} & {$[0,3407]$} \\
\hline \multirow[t]{2}{*}{ IED } & - & - & $-0,00571527$ & $-0,00579541$ & $-0,00546758$ & $-0,0064049$ \\
\hline & - & - & 0,0067 & {$\left[1,66,10^{-5}\right]$} & {$[0,0148]$} & {$\left[1,20.10^{-5}\right]$} \\
\hline \multirow[t]{2}{*}{$\operatorname{IED}(-1)$} & - & - & - & - & $-0,00143909$ & $-0,0021318$ \\
\hline & - & - & - & - & {$[0,5788]$} & {$[0,5746]$} \\
\hline \multirow[t]{2}{*}{$d 02$} & - & $-0,00424362$ & - & $-0,00230164$ & - & $-0,0021916$ \\
\hline & - & {$[0,5631]$} & - & {$[0,7617]$} & - & {$[0,7768]$} \\
\hline \multirow[t]{2}{*}{$d 03$} & - & $-0,00726638$ & - & $-0,00161928$ & - & $-0,0004539$ \\
\hline & - & {$[0,3696]$} & - & {$[0,8583]$} & - & {$[0,9613]$} \\
\hline \multirow[t]{2}{*}{$d 04$} & - & $-0,0127528$ & - & $-0,00693097$ & - & $-0,0046344$ \\
\hline & - & {$[0,1195]$} & - & {$[0,3784]$} & - & {$[0,5918]$} \\
\hline \multirow[t]{2}{*}{$d 05$} & - & $-0,0123295$ & - & $-0,00165682$ & - & 0,0011268 \\
\hline & - & {$[0,2385]$} & - & {$[0,8793]$} & - & {$[0,9132]$} \\
\hline \multirow[t]{2}{*}{$d 06$} & - & $-0,00884452$ & - & 0,00234512 & - & 0,0073711 \\
\hline & - & {$[0,5016]$} & - & {$[0,8604]$} & - & {$[0,4006]$} \\
\hline \multirow[t]{2}{*}{$d 07$} & - & $-0,0162667$ & - & $-0,00615191$ & - & $-0,0013058$ \\
\hline & - & {$[0,0282]$} & - & {$[0,4220]$} & - & {$[0,8890]$} \\
\hline \multirow[t]{2}{*}{$d 08$} & - & $-0,0144145$ & - & $-0,00390025$ & - & 0,0003886 \\
\hline & - & {$[0,1626]$} & - & {$[0,7218]$} & - & {$[0,9655]$} \\
\hline \multirow[t]{2}{*}{$d 09$} & - & $-0,00982602$ & - & 0,00178821 & - & 0,0065225 \\
\hline & - & {$[0,4289]$} & - & {$[0,8920]$} & - & {$[0,5606]$} \\
\hline \multirow[t]{2}{*}{$d 10$} & - & $-0,00833850$ & - & 0,00287488 & - & 0,0077988 \\
\hline & - & {$[0,2541]$} & - & {$[0,7207]$} & - & {$[0,4138]$} \\
\hline \multirow[t]{2}{*}{$d 11$} & - & $-0,00558905$ & - & 0,00678211 & - & 0,0116478 \\
\hline & - & {$[0,4733]$} & - & {$[0,4332]$} & - & {$[0,2064]$} \\
\hline \multirow[t]{2}{*}{$d 12$} & - & $-0,00509177$ & - & 0,00721622 & - & 0,0125611 \\
\hline & - & {$[0,4926]$} & - & {$[0,3697]$} & - & {$[0,1294]$} \\
\hline \multicolumn{7}{|l|}{ Normalidade } \\
\hline - Doornik-Hansen & {$[0,045997]$} & {$[0,496702]$} & {$[0,23572]$} & {$[0,378355]$} & {$[0,246899]$} & {$[0,227896]$} \\
\hline - Shapiro-Wilk & {$[0,144218]$} & {$[0,442886]$} & {$[0,718303]$} & {$[0,80753]$} & {$[0,651498]$} & {$[0,846906]$} \\
\hline - Lilliefors & {$[0,76]$} & {$[0,54]$} & {$[0,59]$} & {$[1,00]$} & {$[0,56]$} & {$[0,79]$} \\
\hline - Jarque-Bera & {$[0,189027]$} & {$[0,568038]$} & {$[0,467472]$} & {$[0,552504]$} & {$[0,431857]$} & {$[0,454245]$} \\
\hline $\mathrm{R}^{2}$ & 0,979671 & 0,983847 & 0,981532 & 0,984866 & 0,981680 & 0,985031 \\
\hline Observação & 58 & 58 & 58 & 58 & 58 & 58 \\
\hline Unidade & 5 & 5 & 5 & 5 & 5 & 5 \\
\hline Chow & {$\left[3,36603 \cdot 10^{-36}\right]$} & {$\left[2,48278 \cdot 10^{-29}\right]$} & {$\left[4,90014 \cdot 10^{-31}\right]$} & {$\left[5,53939.10^{-23}\right]$} & {$\left[1,86131,10^{-30}\right]$} & {$\left[3,15144.10^{-22}\right]$} \\
\hline Breusch-Pagan & {$\left[1,55954.10^{-49}\right]$} & {$\left[8,30142 \cdot 10^{-50}\right]$} & {$\left[2,4134110^{-28}\right]$} & {$\left[8,21049.10^{-34}\right]$} & {$\left[7,78146 \cdot 10^{-29}\right]$} & {$\left[7,78146 \cdot 10^{-29}\right]$} \\
\hline
\end{tabular}

(i) Em colchetes, o p-valor; (ii) A inclusão do IED e do IED defasado de um ano foi apresentada de forma segregada, porque se pretendeu avaliar a diferença dos resultados como reflexo destas variáveis. Como mencionado anteriormente, na literatura mão há constância de trabalhos que avaliem a orientação do IED ao Consumo.

Ao nível de significância de 0,05 adotado neste artigo, os testes de Chow e Breusch-Pagan indicam a existência de heterogeneidade não observada, e os Painéis Estáticos do Modelo de Consumo controlados por Efeitos Fixos (Tabela 2) indicam que a Constante, o Crédito Bancário e a Riqueza Humana são significativos, sendo que o coeficiente desta é negativo, situação contrária do esperado. Quando o IED em nível é incluído, observa-se que seu coeficiente é significativo e negativo, mesmo na situação em que o IED defasado de um ano é considerado.

Para obtenção de resultados mais robustos, considerou-se a inclusão de variáveis dummy de tempo nos painéis (II), (IV) e (VI) da Tabela 2, com a não rejeição da normalidade dos resíduos da regressão em todos os testes. Os coeficientes significativos são os mesmos em que as variáveis dummy não foram acrescentadas e apresentam o mesmo sinal. 
BRICS: LIQUIDEZ, CONSUMO E RELEVÂNCIA DE POLÍTICAS DE PRODUTIVIDADE E DE COMÉRCIO INTERNACIONAL PARA O IED

Tabela 3 - Resultados dos Painéis Dinâmicos do Modelo de Consumo (I) (II) (III) (IV)

\begin{tabular}{|c|c|c|c|c|c|c|c|c|}
\hline \multirow{2}{*}{ Passos } & (I) & (II) & (III) & (IV) & (V) & (VI) & (VII) & (VIII) \\
\hline & MMG Dif & MMG Dif & MMG Sis & MMG Sis & MMG Dif & MMG Dif & MMG Sis & MMG Sis \\
\hline Coeficientes & 1 & 1 & 1 & 1 & 1 & 1 & 1 & 1 \\
\hline \multirow[t]{2}{*}{ Consumo(-1) } & 0,189182 & 0,101890 & 0,957447 & 0,980508 & 0,185124 & 0,104595 & 0,828653 & 0,820869 \\
\hline & {$[0,1252]$} & {$[0,4368]$} & {$\left[5,60.10^{-92}\right]$} & {$\left[7,47 \cdot 10^{-93}\right]$} & {$[0,2034]$} & {$[0,4446]$} & {$\left[2,95.10^{-46}\right]$} & {$\left[4,53 \cdot 10^{-31}\right]$} \\
\hline \multirow[t]{2}{*}{ Constante } & 0,001828 & 0,002340 & 0,013962 & $-0,0212322$ & 0,003667 & 0,004781 & 0,208194 & 0,211958 \\
\hline & {$[0,0169]$} & {$[0,0036]$} & {$[0,7711]$} & {$[0,6714]$} & {$[\mathbf{0 , 5 2 8 6 ]}$} & {$[0,4122]$} & {$[0,0019]$} & {$[0,0136]$} \\
\hline \multirow[t]{2}{*}{ C. Bancário } & 0,106624 & 0,124689 & $-0,004462$ & $-0,00556723$ & 0,117581 & 0,141282 & $-0,030637$ & $-0,032436$ \\
\hline & {$[0,0015]$} & {$[0,0002]$} & {$[0,6368]$} & {$[0,5419]$} & {$[0,0039]$} & {$[0,0005]$} & {$[0,0091]$} & {$[0,0111]$} \\
\hline \multirow[t]{2}{*}{ Riq. Hum. } & $-0,022563$ & $-0,023601$ & 0,004301 & 0,00362872 & $-0,022210$ & $-0,023785$ & 0,001044 & 0,001045 \\
\hline & {$[0,0021]$} & {$[0,0009]$} & {$[0,0006]$} & {$[0,0042]$} & {$[\mathbf{0 , 0 1 5 7 ]}$} & {$[0,0093]$} & {$[0,4703]$} & {$[0,4796]$} \\
\hline \multirow[t]{2}{*}{ Riq. Financ. } & $-2,24211.10^{-6}$ & $-0,000449$ & 0,002703 & 0,00253592 & 0,001307 & 0,002968 & $-0,002065$ & $-0,002919$ \\
\hline & {$[0,9993]$} & {$[0,8619]$} & {$[0,1800]$} & {$[0,2008]$} & {$[\mathbf{0 , 8 7 5 9 ]}$} & {$[0,7128]$} & {$[0,7389]$} & {$[0,6395]$} \\
\hline \multirow{2}{*}{$I E D$} & $-0,005569$ & $-0,005943$ & $-0,001288$ & $-0,00367409$ & $-0,006402$ & $-0,007427$ & $-0,005939$ & $-0,006037$ \\
\hline & {$[0,0225]$} & {$[0,0118]$} & {$[0,3137]$} & {$[0,0191]$} & {$[0,0446]$} & {$[0,0223]$} & {$[0,0005]$} & {$[0,0012]$} \\
\hline \multirow[t]{2}{*}{$\operatorname{IED}(-1)$} & - & $-0,003734$ & 10 & 0,00372221 & - & $-0,004074$ & - & 0,000125 \\
\hline & - & {$[0,1075]$} & - & {$[0,0101]$} & - & {$[0,2056]$} & - & {$[0,9524]$} \\
\hline \multirow[t]{2}{*}{$d 03$} & - & - & - & - & - & - & 0,006886 & 0,006970 \\
\hline & - & - & - & - & - & - & {$[0,0787]$} & {$[0,0811]$} \\
\hline \multirow[t]{2}{*}{$d 04$} & - & - & - & - & $-0,006780$ & $-0,006433$ & 0,006803 & 0,006846 \\
\hline & - & - & - & - & {$[0,4468]$} & {$[0,4565]$} & {$[0,0976]$} & {$[0,1191]$} \\
\hline \multirow[t]{2}{*}{$d 05$} & - & - & - & - & 0,004030 & 0,003206 & 0,015140 & 0,015312 \\
\hline & - & - & - & - & {$[\mathbf{0 , 5 7 3 5 ]}$} & {$[0,6461]$} & {$[0,0012]$} & {$[0,0015]$} \\
\hline \multirow[t]{2}{*}{$d 06$} & - & - & - & - & $-0,003326$ & 0,001123 & 0,010264 & 0,009268 \\
\hline & - & - & - & - & {$[\mathbf{0 , 8 0 9 7 ]}$} & {$[0,9331]$} & {$[0,1719]$} & {$[0,2260]$} \\
\hline \multirow[t]{2}{*}{$d 07$} & - & - & - & - & $-0,005554$ & $-0,009392$ & 0,020846 & 0,021088 \\
\hline & - & - & - & - & {$[0,7019]$} & {$[0,5088]$} & {$[0,0001]$} & {$[0,0009]$} \\
\hline \multirow[t]{2}{*}{$d 08$} & - & - & - & - & $-0,003408$ & $-0,004556$ & 0,011570 & 0,011509 \\
\hline & - & - & - & - & {$[0,7096]$} & [0,6139] & {$[0,0107]$} & {$[0,0259]$} \\
\hline \multirow[t]{2}{*}{$d 09$} & - & - & - & - & $\mathbf{0 , 0 0 1 8 3 7}$ & 0,001730 & 0,015482 & 0,015027 \\
\hline & - & - & - & - & {$[\mathbf{0 , 8 3 2 0}]$} & {$[0,8369]$} & {$[0,0026]$} & {$[0,0065]$} \\
\hline \multirow[t]{2}{*}{ d10 } & - & - & - & - & $-0,000644$ & $-0,002111$ & 0,022743 & 0,022636 \\
\hline & - & - & - & - & [0,9372] & {$[0,7935]$} & {$\left[1,16.10^{-6}\right]$} & {$\left[3,89 \cdot 10^{-5}\right]$} \\
\hline \multirow[t]{2}{*}{$d 11$} & - & - & - & - & $-0,001009$ & $-0,001742$ & 0,022389 & 0,022241 \\
\hline & - & - & - & - & {$[0,8988]$} & {$[0,8230]$} & {$\left[1,18,10^{-5}\right]$} & {$[0,0001]$} \\
\hline \multirow[t]{2}{*}{$d 12$} & - & - & - & - & $-0,004369$ & $-0,003982$ & 0,020404 & 0,020470 \\
\hline & - & - & - & - & {$[0,6131]$} & {$[0,6325]$} & {$[0,0005]$} & {$[0,0033]$} \\
\hline Instrumentos & 43 & 44 & 53 & 54 & 46 & 47 & 63 & 64 \\
\hline Observação & 48 & 48 & 53 & 53 & 48 & 48 & 53 & 53 \\
\hline Unidade & 5 & 5 & 5 & 5 & 5 & 5 & 5 & 5 \\
\hline \multicolumn{9}{|l|}{ Teste AR(1) } \\
\hline $\mathrm{z}$ & $\begin{array}{r}-2,68563 \\
{[0,0072]} \\
\end{array}$ & $\begin{array}{r}-2,59251 \\
{[0,0095]}\end{array}$ & $\begin{array}{r}-4,05895 \\
{[0,0000]}\end{array}$ & $\begin{array}{r}-4,15644 \\
{[0,0000]}\end{array}$ & $\begin{array}{r}-2,67488 \\
{[0,0075]}\end{array}$ & $\begin{array}{r}-2,33956 \\
{[0,0193]}\end{array}$ & $\begin{array}{r}-3,75672 \\
{[0,0002]}\end{array}$ & $\begin{array}{r}-4,12097 \\
{[0,0000]}\end{array}$ \\
\hline \multicolumn{9}{|l|}{ Teste AR(2) } \\
\hline \multirow[b]{2}{*}{ Z } & $-0,986049$ & $-1,60461$ & $-0,29134$ & $-0,137087$ & $-0,98847$ & $-1,63684$ & $-0,18631$ & $-0,178029$ \\
\hline & {$[0,3241]$} & {$[0,1086]$} & {$[0,7708]$} & {$[0,8910]$} & {$[0,3229]$} & {$[0,1017]$} & {$[0,8522]$} & {$[0,8587]$} \\
\hline Sargan & {$[0,2275]$} & {$[0,2004]$} & {$[0,0000]$} & {$[0,0000]$} & {$[0,3361]$} & {$[0,2581]$} & {$[0,0104]$} & {$[0,0170]$} \\
\hline Wald & {$[0,0000]$} & {$[0,0000]$} & {$[0,0000]$} & {$[0,0000]$} & {$[0,0013]$} & {$[0,0013]$} & {$[0,0000]$} & {$[0,0000]$} \\
\hline Wald (dummy) & - & - & - & - & {$[0,9479]$} & {$[0,9666]$} & {$[0,0001]$} & {$[0,0037]$} \\
\hline
\end{tabular}

(i) Em colchetes, o p-valor; (ii) Em negrito, os modelos que passam pelos testes estatísticos; (iii) A inclusão do IED e do IED defasado de um ano foi apresentada de forma segregada, porque se pretendeu avaliar a diferença dos resultados como reflexo destas variáveis. Como mencionado anteriormente, na literatura mão há constância de trabalhos que avaliem a orientação do IED ao Consumo. (iv) Os painéis (V) e (VI) apresentam resultados consistentes com as regressões em que o IED e o IED defasado de um ano não são inclusídos.

Embora os resultados (Tabela 2) para o Crédito Bancário estejam em conformidade com o esperado, os da Riqueza Humana e do IED não estão. Com a finalidade de obtenção de estimativas consistentes em relação à exogeneidade estrita dos regressores, são apresentados os coeficientes dos modelos de painel dinâmico (Tabela 3). O mais apropriado, de acordo com os testes de AR(1), AR(2) Sargan e Wald, é o MMG Dif de um passo.

Na Tabela 3, os painéis (I) e (II) apresentam a Constante, o Crédito Bancário, a Riqueza Humana e o IED como significativos, sendo que os coeficientes da Riqueza Humana e do IED permanecem negativos.

No entanto, ao se controlar as estimativas com as dummies de tempo, no modelo MMG Dif de um passo (Tabela 3) nos painéis (V) e (VI), apenas o Crédito Bancário, a Riqueza Humana e o IED são significativos, com sinais em consonância com as demais regressões até então realizadas. 
Quadro 1 - Modelo de Consumo: comparação entre resultado esperado e os obtidos nas regressões nos painéis (V) e (VI) da Tabela 3

\begin{tabular}{|l|l|l|}
\hline Variável & Resultado Esperado & $\begin{array}{l}\text { Resultado } \\
\text { pelo Coeficiente }\end{array}$ \\
\hline Riqueza Humana & $\begin{array}{l}\text { Espera-se sinal positivo de seu coeficiente na regressão com o } \\
\text { Consumo com base em Davis e Palumbo (2001), Mehra (2001); } \\
\text { Bertaut (2002), Donihue e Avramenko (2007), Shen, Holmes e Lim } \\
(2015) .\end{array}$ & Sinal negativo \\
\hline Riqueza Financeira & $\begin{array}{l}\text { Espera-se sinal positivo de seu coeficiente na regressão com o } \\
\text { Consumo com base em Davis e Palumbo (2001), Mehra (2001), } \\
\text { Bertaut (2002), Donihue e Avramenko (2007) e Shen, Holmes e Lim } \\
(2015) .\end{array}$ & Não foi significativo \\
\hline IED: & $\begin{array}{l}\text { Espera-se relação positiva na regressão do IED com o Consumo com } \\
\text { base em De Angelo, Eunni e Fouto (2010). }\end{array}$ & Sinal negativo \\
\hline Crédito Bancário & $\begin{array}{l}\text { Espera-se sinal positivo de seu coeficiente na regressão com o } \\
\text { Consumo, seguindo o raciocínio de Ellis (2005). }\end{array}$ & Sinal positivo \\
\hline
\end{tabular}

Nas regressões dos painéis (V) e (VI) da Tabela 3 e que são as mais robustas e eficientes, destacam-se a associação positiva do Consumo com o Crédito Bancário (conforme esperado, vide Quadro 1) e a ligação negativa com a Riqueza Humana e com o IED. O coeficiente do Crédito Bancário indica sua relação ter sido maior com o Consumo e no mesmo sentido; o resultado negativo encontrado pelo coeficiente de Riqueza Humana e do IED, distinto daquilo que foi esperado (Quadro 1), pode sinalizar a ligação do maior Consumo com menor Riqueza Humana e menor fluxo de investimento estrangeiro direto.

Desta forma, não foram os incrementos da Riqueza Humana e do IED os elementos mais relevantes associados ao Consumo; os indícios apontam para a ligação do bem-estar material das famílias, representado pelo Consumo, com a ampliação do endividamento do setor privado, estando de acordo com Ellis (2005).

Portanto, como principais resultados econômicos das regressões contidas nos painéis (V) e (VI) da Tabela 3 podem ser destacados:

-Os valores sinalizam a não persistência do Consumo, indicando a ausência de sua inércia, dado que a variável defasada não teve significância estatística. Isto é consonante com Ellis (2005), pois as famílias alteram o seu nível de Consumo, de acordo com o seu acesso ao crédito.

-A influência mais relevante do Crédito Bancário na variação do Consumo também está em consonância com Ellis (2005), dada a relação positiva entre liquidez do setor privado e o Consumo. O sinal negativo obtido pelo coeficiente da Riqueza Humana tem a seguinte possibilidade: como o Consumo é obtido pela razão Consumo/PIB, o crescimento da renda per capita pode sugerir que o aumento da Riqueza Humana estaria relacionado mais à ampliação do PIB do que ao consumo em valores monetários.

-O sinal negativo obtido pelos coeficientes do IED é explicado pelo fato deste ter inclinação maior ao incremento do PIB do que ao do consumo das famílias, o que é factível na hipótese de os investimentos estrangeiros serem atraídos mais pela expectativa de crescimento econômico e de fatores favoráveis a este acontecimento.

Portanto, o consumo das famílias não seria predominante como orientador do IED, mas antes a majoração da produção interna que, caso não seja consumido, poderia ser direcionada ao exterior.

Neste sentido, a expansão do produto e a exportação daquilo que não é consumido localmente tornam-se importantes ao IED e, consequentemente, as políticas voltadas concomitantemente ao estímulo da produtividade e à melhor inserção do BRICS no comércio internacional para direcionar o excedente produzido são relevantes para nortear o IED, o que está alinhado às contribuições de Jadhav (2012), Prabhakar, Azam, Bakhtyar e Ibrahim (2015) e Agrawal (2015). 
-A constante não é significativa e assim as características que diferem entre os países do BRICS e que são constantes no tempo não são relevantes em relação ao Consumo.

-Os resultados obtidos nos painéis (V) e (VI) da Tabela 3 são controlados tanto por características constantes e que variam entre os países como pelas dummies de tempo.

Tabela 4 - Resultados dos Painéis Estáticos do Modelo de Crédito Bancário (i)

\begin{tabular}{|c|c|c|}
\hline Coeficientes & (I) & (II) \\
\hline Constante & $\begin{array}{r}-143,680 \\
{[0,788]}\end{array}$ & $\begin{array}{r}-157,728 \\
{[0,6568]}\end{array}$ \\
\hline \multirow[t]{2}{*}{ Taxa de Empréstimo } & $-165,426$ & $-74,9665$ \\
\hline & {$[0,0000203]$} & {$[0,1165]$} \\
\hline \multirow[t]{2}{*}{ Crédito Não-Performado } & $-85,4449$ & $-70,6148$ \\
\hline & {$[0,0028]$} & {$[0,0596]$} \\
\hline \multirow[t]{2}{*}{ Inflação } & $-8,67399$ & $-33,9402$ \\
\hline & {$[0,9145]$} & {$[0,4158]$} \\
\hline \multirow[t]{2}{*}{ Força do Credor } & 1,0227 & $-8,66478$ \\
\hline & {$[0,8735]$} & {$[0,6314]$} \\
\hline \multirow{2}{*}{ Enforcement } & 38,4922 & 41,4727 \\
\hline & {$[0,6452]$} & {$[0,474]$} \\
\hline \multirow[t]{2}{*}{ Crescimento Econômico } & $-184,069$ & $-118,715$ \\
\hline & {$[0,0000007]$} & {$[0,00000451]$} \\
\hline \multirow[t]{2}{*}{$d 02$} & - & $-13,9038$ \\
\hline & - & {$[0,0281]$} \\
\hline \multirow[t]{2}{*}{$d 03$} & - & $-13,6534$ \\
\hline & - & {$[0,0272]$} \\
\hline \multirow[t]{2}{*}{$d 04$} & - & $-9,95805$ \\
\hline & - & {$[0,1144]$} \\
\hline \multirow[t]{2}{*}{$d 05$} & - & $-5,31529$ \\
\hline & - & {$[0,3154]$} \\
\hline \multirow[t]{2}{*}{$d 06$} & - & $-5,66284$ \\
\hline & - & {$[0,1149]$} \\
\hline \multirow[t]{2}{*}{$d 07$} & - & $-5,42322$ \\
\hline & - & {$[0,2875]$} \\
\hline \multirow[t]{2}{*}{$d 08$} & - & $-0,607098$ \\
\hline & - & {$[0,9106]$} \\
\hline \multirow[t]{2}{*}{$d 09$} & - & $-1,82978$ \\
\hline & - & {$[0,7287]$} \\
\hline \multirow[t]{2}{*}{$d 10$} & - & $-0,996272$ \\
\hline & - & {$[0,8592]$} \\
\hline \multirow[t]{2}{*}{$d 11$} & - & $-2,70673$ \\
\hline & - & {$[0,0187]$} \\
\hline \multicolumn{3}{|l|}{ Teste de Normalidade } \\
\hline Teste de Doornik-Hansen & 0,143928 & 0,124572 \\
\hline Shapiro-Wilk & 0,564652 & 0,20291 \\
\hline Teste de Lilliefors & 0,79 & 0,2 \\
\hline Teste de Jarque-Bera & 0,463975 & 0,340543 \\
\hline $\mathrm{R}^{2}$ & 0,952776 & 0,966628 \\
\hline Observação & 55 & 55 \\
\hline Unidades & 5 & 5 \\
\hline Teste de Chow & {$\left[1,78702 \cdot 10^{-18}\right]$} & {$[0,0000000000000261302]$} \\
\hline Teste de Breusch-Pagan & {$[0,00000775971]$} & 0,000244521 \\
\hline
\end{tabular}

(i) Em colchetes, o p-valor.

\subsection{Modelo de Crédito Bancário: as Relações do Crédito Não-Performado e da Inflação com o Crédito Bancário e Outros Resultados Econômicos}

O Modelo de Crédito Bancário controlado por Efeitos Fixos (Tabela 4) indica que o Crescimento Econômico, a Taxa de Empréstimo e o Crédito Não-Performado são significativos, negativos, sendo merecedora de atenção a situação de o primeiro ter maior influência ao Crédito Bancário e o último o menor. O sinal do coeficiente do Crescimento Econômico é explicado pela possível ligação da desaceleração ou retração das atividades econômicas com as decisões de estímulo de Crédito Bancário.

Embora os testes de Chow e Breusch-Pagan indiquem a existência de heterogeneidade não observada, e a partir dos resíduos deste modelo a não rejeição da hipótese de normalidade ocorra em 
todos os testes, considerou-se a inclusão de dummies de tempo (Tabela 4), para obtenção de resultados mais robustos e avaliar melhor o resultado apurado pelo Crescimento Econômico.

Tabela 5 - Resultados dos Painéis Dinâmicos do Modelo de Crédito Bancário (I) (Ii)

\begin{tabular}{|c|c|c|c|c|}
\hline & (I) & (II) & $\overline{\text { (III) }}$ & $\overline{(I V)}$ \\
\hline & MMG Dif & MMG Sis & MMG Dif & MMG Sis \\
\hline Passos & 1 & 1 & 1 & 1 \\
\hline \multicolumn{5}{|l|}{ Coeficientes } \\
\hline \multirow[t]{2}{*}{ Crédito Bancário (-1) } & $\mathbf{0 , 8 8 7 6 8 5}$ & 0,915845 & 0,948764 & 0,908022 \\
\hline & {$\left[2,15 \cdot 10^{-21}\right]$} & {$[0]$} & {$\left[1,34,19^{-21}\right]$} & {$\left[3,66 \cdot 10^{-197}\right]$} \\
\hline \multirow[t]{2}{*}{ Constante } & 0,132276 & 32,2665 & $-0,855664$ & 31,9859 \\
\hline & {$[0,6536]$} & {$[0,0000000428]$} & {$[0,7332]$} & {$[0,0000024]$} \\
\hline \multirow{2}{*}{ Taxa de Empréstimo } & 10,4701 & $-8,13929$ & $-2,87521$ & $-5,07125$ \\
\hline & {$[0,7035]$} & {$[0,2084]$} & {$[0,925]$} & {$[0,6161]$} \\
\hline \multirow[t]{2}{*}{ Crédito Não-Performado } & $-114,282$ & $-120,221$ & $-118,078$ & $-112,179$ \\
\hline & {$[0,0005]$} & {$\left[4,98,19^{-18}\right]$} & {$[0,038]$} & {$[0,00000000113]$} \\
\hline \multirow[t]{2}{*}{ Inflação } & $-76,9653$ & $-73,0924$ & $-93,2200$ & $-73,3489$ \\
\hline & {$[0,0056]$} & {$[0,0000]$} & {$[0,0018]$} & {$[0,0000]$} \\
\hline \multirow[t]{2}{*}{ Força do Credor } & $\mathbf{0 , 7 2 0 0 0 1}$ & $-1,17350$ & $-\mathbf{0 , 8 5 4 8 4 8}$ & $-1,05222$ \\
\hline & {$[0,8704]$} & {$[0,4524]$} & {$[0,9447]$} & {$[0,6924]$} \\
\hline \multirow[t]{2}{*}{ Enforcement } & $\mathbf{0 , 3 8 8 9 9 2}$ & $-1,78072$ & 3,96087 & $-2,21682$ \\
\hline & {$[0,9873]$} & {$[0,0197]$} & {$[0,8856]$} & {$[0,0254]$} \\
\hline \multirow[t]{2}{*}{ Crescimento Econômico } & $-41,8119$ & $-23,9610$ & $-17,5847$ & 6,37699 \\
\hline & {$[0,0837]$} & {$[0,0065]$} & {$[0,632]$} & {$[0,6706]$} \\
\hline \multirow[t]{2}{*}{$d 03$} & - & - & - & $-1,10689$ \\
\hline & - & - & - & 0,3953 \\
\hline \multirow[t]{2}{*}{$d 04$} & - & - & 2,22151 & 0,323301 \\
\hline & - & - & {$[0,6015]$} & 0,8069 \\
\hline \multirow[t]{2}{*}{$d 05$} & - & - & 1,18761 & 0,424655 \\
\hline & - & - & {$[0,7538]$} & 0,7528 \\
\hline \multirow[t]{2}{*}{$d 06$} & - & - & 1,46167 & 1,26801 \\
\hline & - & - & {$[0,6917]$} & 0,4198 \\
\hline \multirow[t]{2}{*}{$d 07$} & - & - & $3, \mathbf{4 3 1 2 7}$ & 5,15697 \\
\hline & - & - & {$[0,3698]$} & 0,0011 \\
\hline \multirow[t]{2}{*}{$d 08$} & - & - & $-3,36205$ & $-0,11982$ \\
\hline & - & - & {$[0,4218]$} & 0,9303 \\
\hline \multirow[t]{2}{*}{$d 09$} & - & - & 0,488889 & $-0,16219$ \\
\hline & - & - & {$[0,8875]$} & 0,9112 \\
\hline \multirow[t]{2}{*}{$d 10$} & - & - & 1 & 1,85561 \\
\hline & - & - & {$[0,5032]$} & 0,2074 \\
\hline \multirow[t]{2}{*}{$d 11$} & - & - & 0,305 & 1,30642 \\
\hline & - & - & {$[0,9466]$} & 0,4617 \\
\hline \multirow[t]{2}{*}{$d 12$} & - & - & 1 & 1,8829 \\
\hline & - & - & {$[0,7675]$} & 0,2858 \\
\hline Instrumentos & 47 & 57 & 50 & 67 \\
\hline Observação & 50 & 55 & 50 & 55 \\
\hline Unidade & 5 & 5 & 5 & 5 \\
\hline \multicolumn{5}{|l|}{ Teste AR(1) } \\
\hline \multirow[t]{2}{*}{$\mathrm{Z}$} & $-2,47774$ & - & $-2,25754$ & - \\
\hline & {$[0,0132]$} & - & {$[0,0240]$} & - \\
\hline Teste AR(2) & & & & \\
\hline $\mathrm{Z}$ & $-0,555972$ & - & $-0,207773$ & - \\
\hline & {$[0,5782]$} & - & {$[0,8354]$} & - \\
\hline Sargan & {$[0,5148]$} & {$[0,0004]$} & {$[0,5770]$} & {$[0,0001]$} \\
\hline Wald & {$[0,0000]$} & {$[0,0000]$} & {$[0,0000]$} & {$[0,0000]$} \\
\hline Wald (dummy) & & - & {$[0,9197]$} & {$[0,0058]$} \\
\hline
\end{tabular}

(i) Em colchetes, o p-valor; (ii) Em negrito, os modelos que passam pelos testes estatísticos.

No Modelo de Efeito Fixo com dummies de tempo (Tabela 4) os resultados sinalizam que o Crescimento Econômico e algumas dummies são significativos, reforçando o argumento da relevância de medidas anticíclicas da variação do Crédito Bancário, como comentado anteriormente.

Com a finalidade de obtenção de estimativas consistentes em relação à exogeneidade estrita dos regressores, são apresentados os coeficientes dos modelos de painel dinâmico (Tabela 5).

Dentre os modelos de painel dinâmico, o mais apropriado, de acordo com os testes de AR(1), AR(2) Sargan e Wald, é o MMG Dif de um passo (Tabela 5), que indica serem significantes a variável 
dependente defasada, o Crédito Não-Performado e a Inflação, e é notada a persistência do Crédito Bancário.

No painel (III) da Tabela 5, ao se controlar as estimativas do MMG Dif de um passo com as dummies de tempo, o Crédito Não-Performado e a Inflação permanecem significativos, estando de acordo com a literatura (Quadro 2) e os resultados da variável dependente defasada sinalizam inércia do Crédito Bancário, o que pode ser explicado pelo fato não ser facilmente adequado e/ou modificado pelos bancos.

Quadro 2 - Modelo de Crédito Bancário: comparação entre resultado esperado e os obtidos nas regressões no painel (III) da Tabela 5

\begin{tabular}{|c|c|c|}
\hline Variável & Resultado Esperado & $\begin{array}{l}\text { Resultado Obtido pelo } \\
\text { Coeficiente }\end{array}$ \\
\hline $\begin{array}{l}\text { Taxa de } \\
\text { Empréstimo }\end{array}$ & $\begin{array}{l}\text { Espera-se sinal negativo de seu coeficiente, na regressão com o Crédito } \\
\text { Bancário, seguindo o raciocínio de Ellis (2005). }\end{array}$ & Não foi significativo \\
\hline Inflação & $\begin{array}{l}\text { Espera-se sinal negativo do coeficiente, na regressão com o Crédito } \\
\text { Bancário, com base em Cruz (2004) e Warnock e Warnock (2008). }\end{array}$ & Sinal negativo \\
\hline $\begin{array}{l}\text { Crédito Não- } \\
\text { Performado }\end{array}$ & $\begin{array}{l}\text { Em Silipo (2011) e Glen e Mondragón-Vélez (2011), não houve } \\
\text { respostas conclusivas, embora esperassem uma relação negativa entre o } \\
\text { Crédito Não-Performado e o Crédito Bancário. } \\
\text { Espera-se que seja positivamente relacionado com o nível de Crédito }\end{array}$ & Sinal negativo \\
\hline Força do Credor & $\begin{array}{l}\text { Bancário, com base em Haselmann, Pistor e Vig (2006), Djankov et al } \\
\text { (2007), Warnock e Warnock (2008), Bae e Goyal (2009) e De Haas, } \\
\text { Ferreira e Taci (2010). }\end{array}$ & Não foi significativo \\
\hline Enforcement & $\begin{array}{l}\text { Avalia a agilidade do judiciário, esperando-se relação negativa com o } \\
\text { Crédito Bancário, com base em Djankov et al (2007). } \\
\text { O resultado a ser encontrado pode estar de acordo com os ciclos de }\end{array}$ & Não foi significativo \\
\hline $\begin{array}{l}\text { Crescimento } \\
\text { Econômico }\end{array}$ & $\begin{array}{l}\text { Minsky (1992), ou com os choques de Stiglitz e Greenwald (2004). } \\
\text { Dessa forma, avalia-se se as atividades econômicas apresentaram } \\
\text { relação positiva com o Crédito Bancário. }\end{array}$ & Não foi significativo \\
\hline $\begin{array}{l}\text { Crédito Bancário } \\
\text { (Defasado) }\end{array}$ & Não consta na literatura pesquisada & Sinal positivo \\
\hline
\end{tabular}

Portanto, como principais resultados econômicos das regressões contidas no painel (III) da Tabela 5 podem ser destacados:

-O resultado significativo da variável dependente defasada sinaliza a inércia do Crédito Bancário, o que pode ser explicado pelo fato não ser facilmente adequado e/ou modificado pelos bancos.

-Os resultados indicam a possibilidade de que a estabilidade monetária tem relação positiva com a expansão do Crédito Bancário, estando de acordo com a literatura (Quadro 2). Chama atenção a ligação entre a expansão do Crédito Bancário e a ampliação do Consumo, como visto nos resultados das regressões contidos nos painéis (V) e (VI) da Tabela 3 e referentes ao Modelo de Consumo. Assim, na formulação de políticas econômicas é importante avaliar a relação que há no BRICS entre as políticas de estabilidade monetária e uma expansão do Consumo sustentada pelo Crédito Bancário, pois este pode alcançar níveis elevados de difícil adequação, dada a sua inércia observada.

-Os resultados indicam que a redução do Crédito Não-Performado tem relação positiva com a expansão do Crédito Bancário, estando de acordo com a literatura (Quadro 2), pois a previsibilidade de recebimento do crédito pode estimular a oferta pelos bancos.

- A constante não é significativa e assim as características que diferem entre os países do BRICS e que são constantes no tempo não são relevantes em relação ao Crédito Bancário.

-Os resultados obtidos no painel (III) da Tabela 5 são controlados tanto por características constantes e que variam entre os países como pelas dummies de tempo. 


\section{CONCLUSÃO}

\subsection{Da Questão Central, das hipóteses e dos Resultados}

A questão central deste artigo foi: qual a relação do IED e do Crédito Bancário com o Consumo? Para respondê-la, foram aplicadas regressões de dados em painel, e três hipóteses aprofundadas foram:

Hipótese 1: há relação positiva do Crédito Bancário e do IED com o Consumo que teve persistência.

Quanto à Hipótese 1 verificou-se que, enquanto o IED tem relação negativa com o Consumo (distinto do que foi esperado, vide Quadro 1), há a ligação positiva entre o Crédito Bancário e o Consumo (conforme esperado, vide Quadro 1), e que este não tem persistência, o que é consonante com Ellis (2005), pois as famílias alteram o seu nível de Consumo, de acordo com o seu acesso ao crédito.

Hipótese 2: o relacionamento do Consumo com a Riqueza Financeira, o Crédito Bancário e o IED é maior do que com a Riqueza Humana.

Na Hipótese 2, verificou-se a maior relevância do Crédito Bancário para o Consumo.

O sinal negativo obtido pelo coeficiente da Riqueza Humana (distinto do que foi esperado, vide Quadro 1) tem a seguinte possibilidade: como o Consumo é obtido pela razão Consumo/PIB, o crescimento da renda per capita pode sugerir que o aumento da Riqueza Humana estaria relacionado mais à ampliação do PIB do que ao consumo das famílias.

O IED tem inclinação maior ao incremento do PIB do que ao do consumo das famílias, o que é factível na hipótese de os investimentos estrangeiros serem atraídos mais pela expectativa de crescimento econômico e de fatores favoráveis a este acontecimento.

Portanto, o consumo das famílias não é o orientador do IED, mas a majoração da produção interna do país que, caso não seja consumida internamente, pode ser direcionada ao exterior. Neste sentido, as políticas que associam o estímulo da produtividade e a inserção do BRICS no comércio internacional para direcionar o excedente produzido são mais relevantes para nortear o IED, o que está alinhado às contribuições de Jadhav (2012), Prabhakar et al (2015) e Agrawal (2015).

Hipótese 3: a Taxa de Empréstimos, a Inflação, o Crédito Não-Performado, a Força do Credor, o Enforcement e o Crescimento Econômico se relacionam com o Crédito Bancário que tem persistência no tempo.

A Hipótese 3 analisou se a Taxa de Empréstimos, a Inflação, o Crédito Não-Performado, a Força do Credor, o Enforcement e o Crescimento Econômico se relacionam com o Crédito Bancário que tem inércia no tempo.

O Crédito Não-Performado e a Inflação apresentaram associação com o Crédito Bancário (conforme esperado, vide Quadro 2), sendo maior o coeficiente do primeiro. Além disso, foi observada a persistência ao longo do tempo do Crédito Bancário. Dessa forma, a Hipótese 3, em sua integralidade, não foi rejeitada.

\subsection{Das Contribuições}

Portanto, o artigo estudou as associações teóricas das variáveis e a constatação de conjecturas e, com o emprego das regressões de dados em painel, as confrontou com as evidências empíricas, obtidas por meio de proxies. Porém, não pretende esgotar o assunto, mas contribuir de forma interdisciplinar aos debates entre os formuladores de políticas econômicas, cujas decisões afetam a Contabilidade Nacional ao indicar que no BRICS:

-Embora o Crédito Bancário tenha relação positiva com o Consumo e seja utilizado para propiciar maior bem-estar material, caso haja necessidade de se adequar seus níveis a um patamar desejado, haverá dificuldades dada a sua inércia. Assim, é importante ponderar os riscos associados a uma elevação deste bem-estar no curto prazo com o apoio da expansão 
excessiva do Crédito Bancário que pode afetar negativamente a situação econômica no longo prazo. É importante lembrar que até mesmo o FMI (2011) considera o crescimento excessivo do Crédito Bancário uma ameaça à estabilidade econômica;

-O Consumo não é o orientador do IED, mas a majoração da produção interna do país que, caso não seja consumida internamente, pode ser direcionada ao exterior. Neste sentido, as políticas que integram o estímulo da produtividade e a inserção do BRICS no comércio internacional para direcionar o excedente produzido são mais relevantes para nortear o IED. Desta forma, para atrair o IED é relevante que o estímulo da produtividade esteja alinhado ao incentivo às exportações;

-Dada a ligação entre a ampliação do Consumo e a expansão do Crédito Bancário, e entre Crédito Bancário e estabilidade monetária, é importante prudência na formulação de políticas econômicas, pois há no BRICS a relação entre as políticas de estabilidade monetária e de expansão do Consumo sustentada pelo Crédito Bancário, sendo que este pode alcançar níveis elevados de difícil adequação, dada a sua inércia observada. Isso porque embora a estabilidade econômica em um primeiro momento possa estar alinhada ao crescimento do Crédito Bancário, este mesmo Crédito Bancário pode provocar o aumento da instabilidade econômica, caso atinja um patamar elevado;

-Os mecanismos que propiciam maior previsibilidade de recebimento do crédito estimulam a oferta pelos bancos.

\section{REFERÊNCIAS}

Affinito, M., \& Tagliaferri, E. (2010). Why do (or did?) banks securitize their loans? Evidence from Italy. Journal of Financial Stability, 6(4), 189-202.

Aghion, P., \& Bolton, P. (1992). An incomplete contracts approach to financial contracting. The review of economic Studies, 59(3), 473-494.

Agrawal, G. (2015). Foreign direct investment and economic growth in BRICS economies: A panel data analysis. Journal of Economics, Business and Management, 3(4), 421-424.

Araujo, A., \& Funchal, B. (2006). A nova lei de falências brasileira e seu papel no desenvolvimento do mercado de crédito.

Arellano, M., \& Bond, S. (1991). Some tests of specification for panel data: Monte Carlo evidence and an application to employment equations. The review of economic studies, 58(2), 277-297.

Arellano, M., \& Bover, O. (1995). Another look at the instrumental variable estimation of error-components models. Journal of econometrics, 68(1), 29-51.

Bae, K. H., \& Goyal, V. K. (2009). Creditor rights, enforcement, and bank loans. The Journal of Finance, 64(2), 823-860.

Banco Mundial. Disponibiliza dados políticos, sociais e econômicos dos países. <www.worldbank.org> Acesso em março de 2016.

Bertaut, C. C. (2002). Equity prices, household wealth, and consumption growth in foreign industrial countries: wealth effects in the 1990s. FRB International Finance Discussion Paper, (724).

Bhue, G. S., Prabhala, N. R., \& Tantri, P. L. (2015). Creditor rights and relationship banking: Evidence from a policy experiment.

Blundell, R., \& Bond, S. (1998). Initial conditions and moment restrictions in dynamic panel data models. Journal of econometrics, 87(1), 115-143.

Cruz, A. P. D. (2004). Impactos de fatores condicionantes do volume de crédito (Doctoral dissertation, Universidade de São Paulo), Faculdade de Economia, Administração e Contabilidade, Universidade de São Paulo, São Paulo.

Davis, M. A., \& Palumbo, M. G. (2001). A primer on the economics and time series econometrics of wealth effects (Vol. 9). Washington, DC: Divisions of Research \& Statistics and Monetary Affairs, Federal Reserve Board.

De Angelo, C. F., Eunni, R. V., \& Fouto, N. M. M. D. (2010). Determinants of FDI in emerging markets: evidence from Brazil. International Journal of Commerce and Management. 
De Haas, R., Ferreira, D., \& Taci, A. (2010). What determines the composition of banks' loan portfolios? Evidence from transition countries. Journal of Banking \& Finance, 34(2), 388-398.

Deos, S. S. (1998). Instabilidade financeira numa economia de mercado de capitais. Ensaios FEE, 19(2), 3861.

Desai, M. A., Foley, C. F., \& Hines Jr, J. R. (2004). A multinational perspective on capital structure choice and internal capital markets. The Journal of finance, 59(6), 2451-2487.

Diamond, D. W. (2004). Presidential address, committing to commit: short-term debt when enforcement is costly. The Journal of Finance, 59(4), 1447-1479.

Djankov, S., Glaeser, E., La Porta, R., Lopez-de-Silanes, F., \& Shleifer, A. (2003). The new comparative economics. Journal of comparative economics, 31(4), 595-619.

Djankov, S., McLiesh, C., \& Shleifer, A. (2007). Private credit in 129 countries. Journal of financial Economics, 84(2), 299-329.

Donihue, M., \& Avramenko, A. (2007). Decomposing consumer wealth effects: evidence on the role of real estate assets following the wealth cycle of 1990-2002. The BE Journal of Macroeconomics, 7(1).

Ellis, J. H. (2005). Ahead of the Curve: A Commonsense Guide to Forecasting Business And Market Cycle. Harvard Business Review Press.

Esty, B. (2004). When do foreign banks finance domestic projects? New evidence on the importance of legal and financial systems. New Evidence on the Importance of Legal and Financial Systems (September 22, 2004).

Friedman, M. (1957) A theory of the consumption function, Milton General Series, 63, Princeton University Press.

Funchal, B., \& Araujo, A. (2007). A Nova Lei De Falências Brasileira: Primeiros Impactos. XXXV Encontro Nacional de Economia.

Fundo Monetário Internacional. Global Financial Stability Report, 2011. Disponível em < www.imf.org > Acesso: março 2016.

Galindo, A. J., \& Micco, A. (2005). Creditor protection and credit volatility. Inter-american Development Bank.

Glen, J., \& Mondragón-Vélez, C. (2011). Business cycle effects on commercial bank loan portfolio performance in developing economies. Review of Development Finance, 1(2), 150-165.

Hale, G., Razin, A., \& Tong, H. (2006). Institutional Weakness and Stock Price Volatility (No. w12127). National Bureau of Economic Research.

Hale, G., Razin, A., \& Tong, H. (2009). The impact of credit protection on stock prices in the presence of credit crunches (No. w15141). National Bureau of Economic Research.

Hansen, L. P. (1982). Large sample properties of generalized method of moments estimators. Econometrica: Journal of the Econometric Society, 1029-1054.

Hart, O. \& Moore, J. (1994). A theory of debt based on the inalienability of human capital. Quarterly Journal of Economics, 109(1), 841-879.

Hart, O. \& Moore, J. (1998). Default and renegotiation: a dynamic model of debt. Quarterly Journal of Economics, 113(1), 1-42.

Hendry, D. F. (1997). The econometrics of macroeconomic forecasting. The Economic Journal, 107(444), 1330-1357.

Jadhav, P. (2012). Determinants of foreign direct investment in BRICS economies: Analysis of economic, institutional and political factor. Procedia-Social and Behavioral Sciences, 37, 5-14.

Jaffee, D. \& Russell, T. (1976). Imperfect information, uncertainty and credit rationing. Quarterly Journal of Economics, 90(1), 651-666.

Jappelli, T., \& Pagano, M. (2002). Information sharing, lending and defaults: Cross-country evidence. Journal of Banking \& Finance, 26(10), 2017-2045.

Jappelli, T., Pagano, M., \& Bianco, M. (2005). Courts and banks: Effects of judicial enforcement on credit markets. Journal of Money, Credit and Banking, 223-244.

La Porta Drago, R., Lopez-de-Silanes, F., Shleifer, A., \& Vishny, R. (1996). Law and finance. NBER working paper, 5661.

La Porta, R., Lopez-De-Silanes, F., Shleifer, A \& Vishny, R. (1997). Legal determinants of external finance. Journal of Finance, 52(1), 1131-1150.

La Porta, R., Lopez-De-Silanes, F., Shleifer, A. \& Vishny, R. (1999) The quality of government, Journal of Law, Economics, and Organization, 15(1), 222-279. 
La Porta, R., Lopez-De-Silanes, F., Shleifer, A. \& Vishny, R. (2000). Investor protection and corporate governance, Journal of Financial Economics, 58(1), 3-27.

La Porta, R., Lopez-De-Silanes, F., Shleifer, A. \& Vishny, R. (2002). Investor protection and corporate valuation, Journal of Finance, 57(1), 1147-1170.

La Porta, R., Lopez-De-Silanes, F., Shleifer, A. and Vishny, R. (1998). Law and finance. Journal of Political Economy, 106(1) 1113-1155.

Laskar, S. (2015). Determinants of Trade and FDI flows in the BRICS countries-Evidences from Gravity Model Analysis (Doctoral dissertation). Department of Humanities and Social Sciences, National Institute of Technology, Rourkela In partial fulfilment of the requirement of the award of the Degree of Master of Arts in Development Studies.

Mehra, Y. P. (2001). The wealth effect in empirical life-cycle aggregate consumption equations. FRB Richmond Economic Quarterly, 87(2), 45-68.

Mian, A. (2006). Distance constraints: The limits of foreign lending in poor economies. The Journal of Finance, 61(3), 1465-1505.

Minsky, H. P. (1992). The financial instability hypothesis. The Jerome Levy Economics Institute Working Paper, (74).

Modigliani, F., \& Brumberg, R. (1954). Utility analysis and the consumption function: An interpretation of cross-section data. Franco Modigliani, 1(1), 388-436.

Mulligan, C. B., \& Shleifer, A. (2005). The Extent of the Market and the Supply of Regulation. The Quarterly Journal of Economics, 120(4), 1445-1473.

Pagano, M. \& Jappelli, T. (1993) Information sharing in credit markets. Journal of Finance, 43(1), 16931718.

Prabhakar, A. C., Azam, M., Bakhtyar, B., \& Ibrahim, Y. (2015). Foreign direct investment, trade and economic growth: A new paradigm of the BRICS. Modern Applied Science, 9(12), 32-42.

Saito, A. T. (2012). Fatores determinantes da disponibilidade de crédito nos países: uma análise de 2004 a 2010 (Doctoral dissertation, Universidade de São Paulo). Faculdade de Economia, Administração e Contabilidade, Universidade de São Paulo, São Paulo, 2012.

Saito, A. T., Savoia, J. R., \& Lazier, I. (2013). Fatores determinantes da disponibilidade de crédito nos países. Revista Economia \& Gestão, 13(32), 45-67.

Sapienza, P. (2002). The effects of banking mergers on loan contracts. The Journal of finance, 57(1), 329367.

Sargan, J. D. (1958). The estimation of economic relationships using instrumental variables. Econometrica: Journal of the Econometric Society, 393-415.

Shen, X., Holmes, M. J., \& Lim, S. (2015). Wealth effects and consumption: a panel VAR approach. International Review of Applied Economics, 29(2), 221-237.

Silipo, D. B. (2011). It happened again: A Minskian analysis of the subprime loan crisis. Journal of Economics and Business, 63(5), 441-455.

Stiglitz, J. E., \& Greenwald, B. (2004). Rumo a um novo paradigma em economia monetária. Francis.

Stiglitz, J. E., \& Weiss, A. (1981). Credit rationing in markets with imperfect information. The American economic review, 71(3), 393-410.

Townsend, R. M. (1979). Optimal contracts and competitive markets with costly state verification. Journal of Economic theory, 21(2), 265-293.

Tsai, H., Chang, Y., \& Hsiao, P. H. (2011). What drives foreign expansion of the top 100 multinational banks? The role of the credit reporting system. Journal of Banking \& Finance, 35(3), 588-605.

Vijayakumar, N., Sridharan, P., \& Rao, K. C. S. (2010). Determinants of FDI in BRICS Countries: A panel analysis. International Journal of Business Science \& Applied Management (IJBSAM), 5(3), 1-13.

Warnock, V. C., \& Warnock, F. E. (2008). Markets and housing finance. Journal of Housing economics, 17(3), 239-251.

Windmeijer, F. (2005). A finite sample correction for the variance of linear efficient two-step GMM estimators. Journal of econometrics, 126(1), 25-51.

Wooldridge, J. M. (2010). Econometric analysis of cross section and panel data. MIT press. 